\title{
Comparative Study
}

\section{Psychological Distress among Employed, Partially employed and Unemployed Youths Due to Pandemic: A Comparative Study}

\author{
Inchara Chamaiah Swamy ${ }^{1 *}$
}

\section{ABSTRACT}

Novel corona virus, COVID-19 has been declared as pandemic by the WHO (world health organization). The spread of corona virus has lead to wide spread fear which in turn has affected the daily life of every individual, more so the unemployed youths. The present study aimed to examine the level of psychological distress among employed, Partially employed and unemployed youths. The research was conducted on 101 youths in the age range of 18-35 years. The sample of the study consisted 60 unemployed and 41 employed Indian youths. Random sampling method was used in order to select the subject's for the present study. Online survey method was adopted for the collection of data. Kessler Psychological distress Scale, (K10) was used to assess the level of psychological distress. In order to analyze the data mean, SD, " $t$ " test and "f" test was used. The wide spread contagious outbreak has brought a halt to the fast moving modern world. Thus, this disease has affected every individual directly or indirectly. Such a change in one's life has caused anxiety, stress and fear, though this is a natural reaction to an uncertain situation. The data reveals that there's an alarming need to cope and manage the impact of the disease among unemployed youths to ensure good health and wellbeing.

Keywords: COVID-19, Pandemic, Psychological Distress, Partially employed, Unemployed, Youths

OVID-19 outbreak has led to widespread fear and anxiety about one's future, its true
more so among unemployed youths. When a person searching for employment is
unable to find work then he or she is an unemployed. Unemployment is often used to
measure the economy of a country. The rate of unemployment in India was $9.21 \%$ from
$2018-2020$ it, has reached an all time high of $23.50 \%$ in April 2020 due to the pandemic.
There are many types of unemployment in India they are disguised unemployment, seasonal
unemployment, structural unemployment, cyclical unemployment, technological
unemployment and frictional unemployment. Unemployment can be caused due to various
reasons such as large population, low educational levels, inadequate infrastructure,
inadequate investments, low productivity etc. Major problem due to unemployment is
poverty. Unemployment most frequently affects young adults this decreases their confidence
and self esteem which further leads to psychological distress. Pavlina R. Tcherneva (2017)

${ }^{1}$ Assistant Professor, Department of Psychology, Christ College, Mysuru, Karnataka, India *Corresponding Author

Received: July 05, 2021; Revision Received: September 11, 2021; Accepted: September 30, 2021

(C) 2021, Swamy I.C.; licensee IJIP. This is an Open Access Research distributed under the terms of the Creative Commons Attribution License (www.creativecommons.org/licenses/by/2.0), which permits unrestricted use, distribution, and reproduction in any Medium, provided the original work is properly cited. 


\section{Psychological Distress among Employed, Partially employed and Unemployed Youths Due to Pandemic: A Comparative Study}

rightly stated that, "Unemployment seems to behave like a virus, or an epidemic, and it is incumbent on economists and policymakers to examine and treat it as one". Young individuals tend to indulge in illegal activities in the pressure of earning money. There are chances of unemployed individuals getting involved in anti social activities, this may be done due to loss of faith in democratic values. Unemployment is a serious issue when it comes to third world countries particularly India which has second largest population. Under employment and disguise employment also is an add on to the problem of unemployment in India. Joining a job is usually considered as upward social mobility therefore this enhances the expectation of a job seeker. However a college degree does not guarantee employment, this has been encountered after 1990s. Andrew E.Clark, Anthony Lepinteur (2019) rightly observed and stated that it is assured that there is highly significant association between family income and psychological distress of unemployed youths. Pandemic has created a kind of financial crisis due to decreased mobility of finances. This further has affected the labor market, wherein many have lost their jobs during the pandemic. Unemployed individual's experience various physical social and psychological problems, amongst them youths are the most affected as they are prone to substance abuse suicides and accidents. Unemployed youths suffer from feeling of emptiness, hopelessness, shame, worthlessness, sadness, anger, low self-esteem, frustration and social exclusion this influences their identity. Most of the studies suggest that psychological distress leads to unemployment and unemployment leads to psychological distress. Need for the current study is justified by the importance of identifying the factors triggering psychological distress among working and unemployed youths. This study opens up the possibility of generating information that contributes to policy making and also leads to an understanding among youths regarding impact of COVID 19 pandemic among working and unemployed youths.

\section{MATERIAL AND METHODS}

\section{Sample}

The sample consisted of 101 youths, who were the residents of Karnataka, India. The sample encompasses 53 females and 48 males, in the age range of 18-35 years. The respondents were from various parts of Karnataka. The sample of the study consisted 60 unemployed and 41 employed youths. Random sampling method was used in order to select the subject's for the present study. Online survey method was adopted for the collection of data.

\section{Objectives of the study}

- To study the level of psychological distress among youths.

- To study the difference in the level of psychological distress among male and female youths.

- To understand the difference in the level of psychological distress among employed and unemployed youths.

- To observe the relationship between the level of psychological distress and family income.

\section{Hypothesis of the study}

H1: The level of psychological distress is high among youths.

$\mathrm{H} 2$ : The level of psychological distress is high among female than male.

H3: The level of psychological distress is high among unemployed youths than their employed counterparts.

H4: The level of psychological distress is high among low and middle income group youths. 


\section{Research tools used in the study}

Kessler Psychological distress Scale, (K10)

Kessler Psychological distress Scale, was developed by Kessler R. Professor of Health Care Policy, Harvard Medical School, Boston, USA, this scale contains 10 valid items. This selfreport measure is a questionnaire intended to yield a global measure of psychological distress based on questions about anxiety and depressive symptoms that a person has experienced in the most recent 4 week that is 30 days period. This Scale is a measure of psychological distress. Each question has five options; these options were scored from one to five. The numbers attached to the samples 10 responses are added up and the total score is the score on the Kessler Psychological Distress Scale (K10).

Scores will range from 10 to 50 .

- A score below 20 are likely to be well.

- A score 20-24 are likely to have a mild Psychological Distress.

- A score 25-29 are likely to have moderate Psychological Distress.

- A score 30 and over are likely to have a severe Psychological Distress.

Scale Administration: Kessler Psychological distress Scale was administered through online survey mode using Google forms to collect information about the samples current condition, hence when completing the K10 questionnaire the samples were provided with privacy.

\section{Statistical Techniques in analyzing the data}

Based on the objectives and hypothesis of the study, mean, SD, " $t$ " test and "f" test were used to analyze the raw data, which was collected through online survey method.

\section{RESULTS AND DISCUSSION}

In this section, the researcher has tried to assess the level of psychological distress among youths using the Kessler Psychological distress Scale.

The data obtained was analyzed as below:

Relationship between Psychological Distress and Gender Graph No.1: Mean Score of Psychological distress among youths.

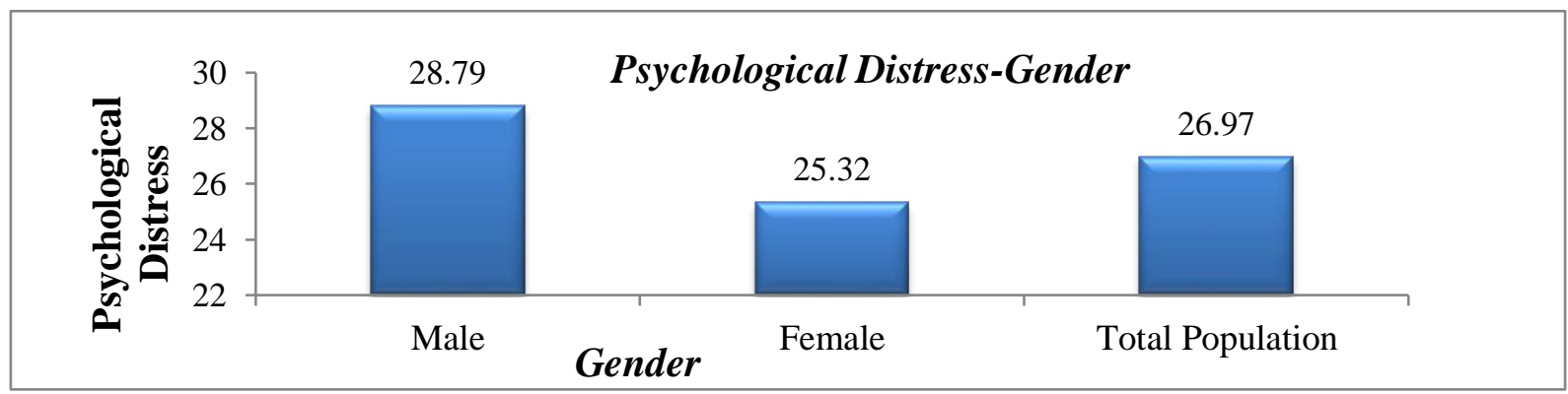

Table No.1: Psychological distress among youths: male and female.

\begin{tabular}{|l|l|l|l|}
\hline Group & Male & Female & Total Population \\
\hline Mean & 28.79 & 25.32 & 26.97 \\
\hline Standard Deviation & 10.28 & 8.10 & 9.32 \\
\hline SEM & 1.48 & 1.11 & 0.92 \\
\hline N & 48 & 53 & 101 \\
\hline t-value & 1.87 & \\
\hline p-value & 0.065 & \\
\hline
\end{tabular}




\section{Psychological Distress among Employed, Partially employed and Unemployed Youths Due to Pandemic: A Comparative Study}

The above table reveals the level of psychological distress among youths. The overall mean score of 26.97 revealed a moderate level of psychological distress among youths. The mean score among male and female was 28.79 and 25.32 respectively, though the scores indicate a slightly greater score among males, the level of psychological distress among both the group is a moderate. Henceforth there was no significant difference in the level of psychological distress among male and female youths. Therefore, the hypothesis of the study that is female have greater psychological distress than their male counterparts is disproved. This finding is similar to the study done by Thoroddur Bjarnason and Thordis J. Sigurdardottir (2003). However the psychological distress among total population revealed a moderate level of psychological distress, this proves the hypotheses that youths have a greater level of Psychological distress.

Relationship between Psychological Distress and Employment Status Graph No.2: Mean Score of Psychological distress among employed, Partially employed and unemployed youths

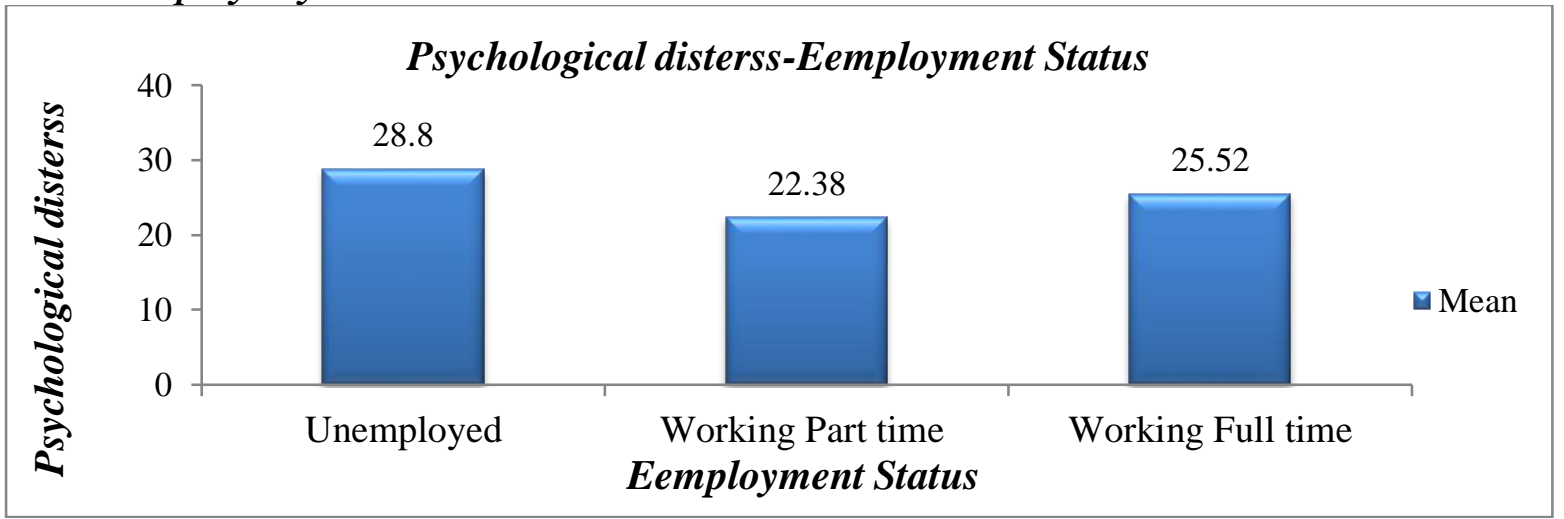

Table No.2: Psychological distress among employed, Partially employed and unemployed youths

\begin{tabular}{|l|l|l|l|l|}
\hline Group & Unemployed & Working Part time & Working Full time & Total \\
\hline Mean & 28.80 & 22.38 & 25.52 & 26.97 \\
\hline SD & 9.45 & 5.36 & 9.99 & 9.09 \\
\hline SEM & 1.22 & 1.34 & 1.99 & 0.92 \\
\hline N & 60 & 16 & 25 & 101 \\
\hline f-value & 3.57 & & \\
\hline p-value & 0.032 & \multicolumn{3}{l|}{} \\
\hline
\end{tabular}

The above table reveals the level of psychological distress among the employed and unemployed youths. The samples were categorized as unemployed, working part time and working full time based on their employment status. The mean scores of levels of psychological distress among unemployed youths, youths working part time and the youths working full time was $28.80,22.38,25.52$ respectively. The scores indicated that youths working part time had mild psychological distress whereas the unemployed and full-time working youths had moderate level of psychological distress. Henceforth there was a significant difference in the level of psychological distress among the employed and unemployed youths. Therefore, the hypothesis of the study that is, the level of psychological distress is high among unemployed youths than there employed counterparts is proved. This finding is similar to that of study done by Thoroddur Bjarnason and Thordis J. Sigurdardottir (2003), which stated that "males and females who had found temporary employment were 


\section{Psychological Distress among Employed, Partially employed and Unemployed Youths Due to Pandemic: A Comparative Study}

less distressed than their continuously unemployed counterparts but more distressed than who had found permanent employment".

Relationship between psychological distress and family income Graph No.3: Mean Scores depicting relation between Psychological distress and Family Income

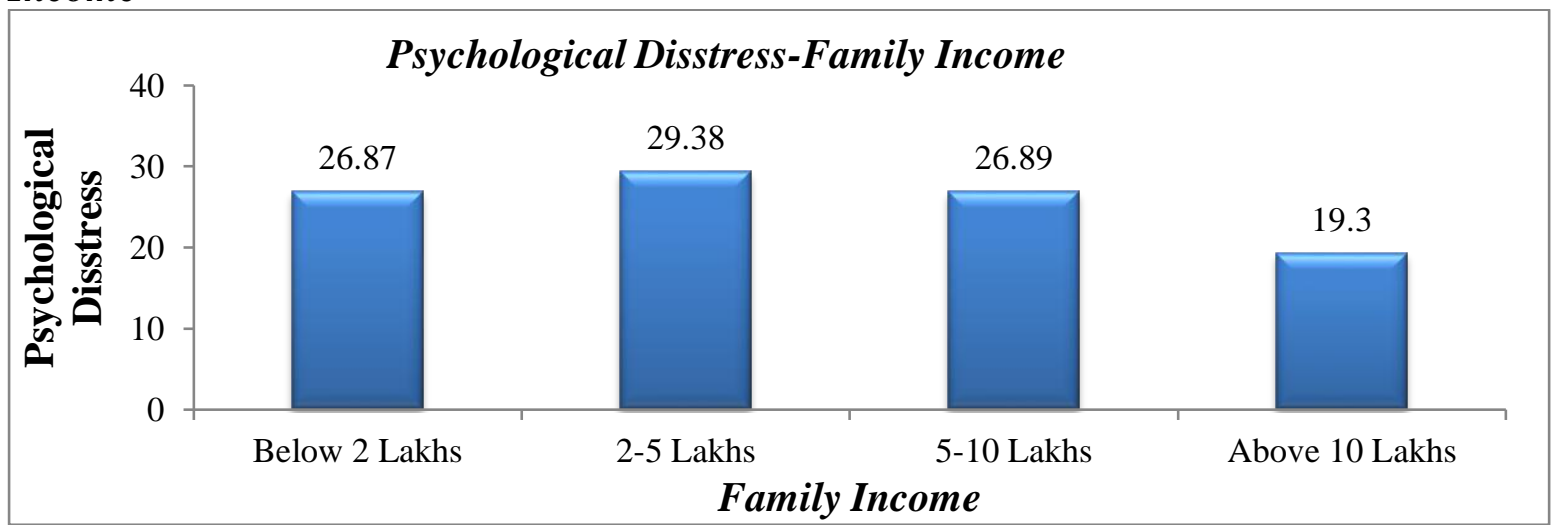

Table No.3: Relationship between Psychological distress and Family Income.

\begin{tabular}{|l|l|l|l|l|}
\hline $\begin{array}{l}\text { Family Income } \\
\text { in Lakhs }\end{array}$ & $\begin{array}{l}\text { Below 2 } \\
\text { Lakhs }\end{array}$ & 2-5 Lakhs & 5-10 Lakhs & Above 10 Lakhs \\
\hline Mean & 26.87 & 29.38 & 26.89 & 20.30 \\
\hline SD & 9.59 & 8.04 & 9.23 & 9.58 \\
\hline SEM & 1.55 & 1.38 & 2.11 & 3.03 \\
\hline N & 38 & 34 & 19 & 10 \\
\hline f-value & 3.219 & \multicolumn{5}{|l}{} \\
\hline p-value & 0.026 &
\end{tabular}

The above table reveals the relationship between family income and psychological distress. The samples were categorized based on annul family income and the scores were further analyzed. The mean score of level of psychological distress among youths having family income below 2lakhs, 2-5lakhs, 5-10lakhs and above 10lakhs was 26.87, 29.38, 26.89 and 19.30 respectively. The scores indicated that youths who had low to medium annual income had moderate psychological distress whereas youths had who had high annual income had mild level of psychological distress. Henceforth there was a significant difference in the level of psychological distress among youths who were categorized based on family income. Therefore, the hypothesis of the study that is, the level of psychological distress is high among low and middle income group youths is proved.

Andrew E.Clark, Anthony Lepinteur (2019) rightly observed and stated that it is assured that there is highly significant association between family income and psychological distress of unemployed youths.

\section{CONCLUSION}

- The research study revealed that youths had mild level of psychological distress during the COVID-19 pandemic.

- The scores indicated that, both male and female youths had moderate level of psychological distress. Thus, there was no significant difference in the level of psychological distress among male and female.

(c) The International Journal of Indian Psychology, ISSN 2348-5396 (e) | ISSN: 2349-3429 (p) | 2033 


\section{Psychological Distress among Employed, Partially employed and Unemployed Youths Due to Pandemic: A Comparative Study}

- The study revealed that psychological distress among youths working part time had mild psychological distress whereas the unemployed and full-time working youths had moderate level of psychological distress. Henceforth there was a significant difference in the level of psychological distress among the employed and unemployed youths.

- The study revealed that psychological distress among youths having low to middle annual income had moderate psychological distress whereas youths had who had high annual income had mild level of psychological distress. Henceforth the level of psychological distress was comparatively more among low and middle income group youths.

\section{REFERENCES}

Andrew E.Clark, Anthony Lepinteur(2019). "The causes and consequences of early-adult unemployment: Evidence from cohort data" Journal of Economic Behavior and Organization 166,107-124

Andrews, G., Slade, T (2001). "Interpreting scores on the Kessler Psychological Distress Scale (k10)". Australian and New Zealand Journal of Public Health, 25, 494-497.

Anne Reneflot and Miriam Evensen (2014). "Unemployment and psychological distress among young adults in the Nordic countries: A review of the literature" International Journal of Social welfare, 23: 3-15

Asfiya Kidwai and Zain Sarwar (2015). "Psychological Impacts of Unemployment Evidence from the Literature", Society of Interdisciplinary Business Research, vol.4(3), 141-152

Christopher T. Whelan (1994). "Social Class, Unemployment, and Psychological Distress", European Sociological Review, Vol. 10, 49-61

Damian F. Hannan, Sea N O Riain and Christopher T. Whelan (1997). "Youth unemployment and psychological distress in the Republic of Ireland" Journal of Adolescence, 20, 307-320

Kessler, R.C., Andrews, G. Colpe, .et al (2002)." Short screening scales to monitor population prevalence's and trends in non-specific psychological distress". Psychological Medicine, 32, 959-956.

M. Daly and L. Delaney (2013). "The scarring effect of unemployment throughout adulthood on psychological distress at age 50: Estimates controlling for early adulthood distress and childhood psychological factors" Social Science \& Medicine, 80: $19-23$

Mushtaq Ahmad Bhat and Jyotsna Joshi (2020). "Impact of Unemployment on the Mental Health of Youth in the Kashmir Valley", Journal of Psychology and Psychotherapy, Vol.10 No:373

Pavlina R. Tcherneva (2017). "Unemployment: The Silent Epidemic", Levy Economics Institute, Working Paper No. 895

Thoroddur Bjarnason and Thordis J. Sigurdardottir (2003). "Psychological Distress during Unemployment and Beyond: Social Support and Material Deprivation Among Youth in Six Northern European Countries" Social Science \& Medicine 56. 973-985

\section{Acknowledgement}

I would like to express my deepest gratitude to all the participants in my study who have willingly shared their information by devoting their precious time. 
Psychological Distress among Employed, Partially employed and Unemployed Youths Due to Pandemic: A Comparative Study

\section{Conflict of Interest}

The author(s) declared no conflict of interest.

How to cite this article: Swamy I.C. (2021). Psychological Distress among Employed, Partially employed and Unemployed Youths Due to Pandemic: A Comparative Study. International Journal of Indian Psychology, 9(3), 2029-2035. DIP:18.01.191.20210903, DOI:10.25215/0903.191 